\title{
On resonant mixed Caputo fractional differential equations
}

\author{
Assia Guezane-Lakoud ${ }^{1}$ and Adem Kılıçman² ${ }^{2^{*}}$
}

${ }^{\text {*Correspondence: }}$

akilic@upm.edu.my

${ }^{2}$ Department of Mathematics and Institute for Mathematcal Research, Universiti Putra Malaysia, 43400, Serdang, Malaysia

Full list of author information is available at the end of the article

\begin{abstract}
The purpose of this study is to discuss the existence of solutions for a boundary value problem at resonance generated by a nonlinear differential equation involving both right and left Caputo fractional derivatives. The proofs of the existence of solutions are mainly based on Mawhin's coincidence degree theory. We provide an example to illustrate the main result.
\end{abstract}

Keywords: Boundary value problems (BVPs); Mawhin's coincidence degree; Fractional derivatives; Existence of solution; Resonance

\section{Introduction and preliminaries}

Mathematical structures describe the complex systems which involve multiple elements and interact between one another in various forms. These interactions exist in physics, electromagnetic, mechanics, biology, signal processing, finance, economics, and many more. In order to make sense of the data extracted from such elements, the evolution of the data against time is utilized. The immediate observation would be a system of differential equations. Upon solving such differential equations, the obtained function will have some information that can be used to extract and understand the data at hand and further predict the future information related to the data. A special class of differential equations are boundary value problems (BVP) and nonlinear fractional integro-differential equations $[1,2]$. The fundamental investigation on these types of fractional differential equations is pertinent in order to interpret the related data which evolve into such form. Thus to study the solutions of existence and uniqueness of integro-differential equations might benefit data modeling and formulation via fractional integro-differential equations.

Further, BVPs containing fractional derivatives also describe many phenomena in various modeling such as in science and engineering, in particular viscoelasticity, physics, electromagnetism, biology as well as finance, in particular mixed fractional option pricing, and more. The questions linked to the existence of solutions to BVPs for fractional differential equations have been studied by researchers using different methods, here we cite some such as fixed point theorems, the upper and lower solutions, Mawhin's coincidence degree theory, Laplace transform method, iteration methods, etc. [3-22].

In [23], the existence of solutions for integral boundary value problems of mixed fractional differential equations under resonance was studied, and a very recent study [24] in-

(c) The Author(s) 2020. This article is licensed under a Creative Commons Attribution 4.0 International License, which permits use sharing, adaptation, distribution and reproduction in any medium or format, as long as you give appropriate credit to the original author(s) and the source, provide a link to the Creative Commons licence, and indicate if changes were made. The images or other third party material in this article are included in the article's Creative Commons licence, unless indicated otherwise in a credit line to the material. If material is not included in the article's Creative Commons licence and your intended use is not permitted by statutory regulation or exceeds the permitted use, you will need to obtain permission directly from the copyright holder. To view a copy of this licence, visit http://creativecommons.org/licenses/by/4.0/. 
troduced a new method to convert the boundary value problems for impulsive fractional differential equations to integral equations.

Recently much attention has been given to the solvability of such type of differential equations that have left and right fractional derivatives. Further, several works are also devoted to this type of study, for details, see [3, 4, 7, 12-14].

In this study, we consider the existence of solutions for the following type of equation:

(P) $\left\{\begin{array}{l}D_{1^{-}}^{\theta} D_{0^{+}}^{v} x(t)=f(t, x(t)), \quad t \in(0,1), \\ x(0)=0, \quad D_{0^{+}}^{v} x(1)=D_{0^{+}}^{v} x(0),\end{array}\right.$

where $f \in C([0,1] \times \mathbb{R}, \mathbb{R}), 0<\theta$, and $v<1$ such that $\theta+v>1$, while the notations $D_{1^{-}}^{\theta}$ and $D_{0^{+}}^{v}$ refer to the right and left fractional derivatives in the Caputo sense, respectively. Note that problem $(\mathrm{P})$ is at resonance since the homogeneous fractional boundary value problem (BVP)

$$
\begin{aligned}
& D_{1^{-}}^{\theta} D_{0^{+}}^{\nu} x(t)=0, \quad t \in(0,1), \\
& x(0)=0, \quad D_{0^{+}}^{\nu} x(1)=D_{0^{+}}^{v} x(0)
\end{aligned}
$$

has $x(t)=c t^{v}, c \in \mathbb{R}$ as nontrivial solutions.

In this study we establish sufficient conditions that will help us to show that there is at least one solution for problem (P). Many difficulties will occur when we deal with the presence of mixed type fractional derivatives having order less than one, and there are only a few studies related to this case. Moreover, the current literature on the study of BVP at resonance having mixed type fractional-order derivatives is not satisfactory and the topic has not been extensively studied so far. There are some initial attempts such as the following.

In [9], the authors studied, by means of Mawhin's coincidence degree, the existence of solutions in multipoint Riemann-Liouville sense fractional BVP on the half-line:

$$
\begin{aligned}
& D_{0^{+}}^{\alpha} u(t)=f\left(t, u(t), D_{0^{+}}^{\alpha} u(t)\right), \quad t>0,1<\alpha<2, \\
& I_{0^{+}}^{2-\alpha} u(0)=0, \quad \lim _{t \rightarrow \infty} D_{0^{+}}^{\alpha-1} u(t)=\sum_{i=1}^{m-2} \beta_{i} D_{0^{+}}^{\alpha-1} u\left(\xi_{i}\right),
\end{aligned}
$$

where $0<\xi_{1}<\cdots<\xi_{m-2}<\infty, \beta_{i}>0$, and $i=1, \ldots, m-1$.

In [4], the authors investigated the existence and uniqueness of solution by the use of some fixed point theorems for the following type BVP:

$$
\begin{aligned}
& { }^{C} D_{1^{-}}^{\alpha R L} D_{0^{+}}^{\beta} u(t)+\lambda I_{0^{+}}^{p} I_{1^{-}}^{q} h(t, u(t))=f(t, u(t)), \quad t \in(0,1) \\
& u(0)=u(\xi)=0, \quad u(1)=\delta u(\mu),
\end{aligned}
$$

where $1<\alpha<2,0<\beta<1,0<\xi<\mu<1$.

Similarly, under certain conditions on $f$ in [14], the authors studied and proved, by using Krasnoselskii's fixed point theorem, the existence of solutions for the following type nonlinear BVPs:

$$
{ }^{C} D_{1^{-}}^{\alpha} D_{0^{+}}^{\beta} u(t)=f(t, u(t)), \quad t \in(0,1),
$$




$$
u(0)=u^{\prime}(0)=u(1)=0
$$

which involve the right Caputo and the left Riemann-Liouville fractional derivatives, respectively.

In $[19,20]$, some partial treatments were provided for the following hybrid type nonlinear fractional integro-differential equations:

$$
\begin{aligned}
& \left(D^{\alpha} u\right)(t)+\lambda u(t)=f\left(t, u(t), \int_{t_{0}}^{t} \frac{(t-s)^{\alpha-1}}{\Gamma(\alpha)} g(s, u(s)) d s\right) \\
& u\left(t_{0}\right)=B_{0} \in \mathbb{R}
\end{aligned}
$$

where $f, g$ are continuous functions and $\lambda \in \mathbb{R}^{+}$for all $t \in J=[a, b]$. Thus we check for a solution of Eq. (1) subject to $u \in C^{1}(J, \mathbb{R})$.

Next we recall the following definitions and auxiliary lemmas related to fractional calculus theory, for details, see [17, 22, 25].

Definition 1 The left and right Riemann-Liouville fractional integrals with order $\theta>0$ on $[a, b]$ of a function $y$ are defined respectively by

$$
\begin{aligned}
& I_{a^{+}}^{\theta} y(t)=\frac{1}{\Gamma(\theta)} \int_{a}^{t}(t-s)^{\theta-1} y(s) d s, \quad t>a, \\
& I_{b^{-}}^{\theta} y(t)=\frac{1}{\Gamma(\theta)} \int_{t}^{b}(s-t)^{\theta-1} y(s) d s, \quad t<b .
\end{aligned}
$$

Definition 2 The left and right Caputo derivatives $D_{a^{+}}^{\alpha}$ and $D_{b^{-}}^{\alpha}$ with order $\alpha>0$ on $[a, b]$ of the function $y \in A C^{n}[a, b]$ are defined by

$$
\begin{aligned}
& D_{a^{+}}^{\theta} y(t)=\frac{1}{\Gamma(n-\theta)} \int_{a}^{t}(t-s)^{n-\theta-1} y^{(n)}(s) d s, \quad t>a \\
& D_{b^{-}}^{\theta} y(t)=\frac{(-1)^{n}}{\Gamma(n-\theta)} \int_{t}^{b}(s-t)^{n-\theta-1} y^{(n)}(s) d s, \quad t<b
\end{aligned}
$$

respectively, where $n=[\theta]+1$, and $[\theta]$ is the integer part of $\theta$.

In the next lemma we present some properties associated with fractional integrals and derivatives in the Caputo sense.

Lemma 3 The homogenous equation (fractional differential)

$$
D_{a^{+}}^{\theta} g(t)=0
$$

has a solution

$$
g(t)=\sum_{i=0}^{n-1} c_{i}(t-a)^{i}
$$

and similarly,

$$
D_{b^{-}}^{\theta} g(t)=0
$$


has a solution

$$
g(t)=\sum_{i=0}^{n-1} a_{i}(b-t)^{i},
$$

where $a_{i}, c_{i} \in \mathbb{R}, i=1, \ldots, n$, and $n=[\theta]+1$ if $\theta \notin \mathbb{N}=\{0,1, \ldots\}$ and $n=\theta$ if $\theta \in \mathbb{N}$.

In addition, the following properties are correct:

$$
\begin{aligned}
& D_{a^{+}}^{\theta} I_{a^{+}}^{\theta} y(t)=y(t), \quad D_{b^{-}}^{\theta} I_{b^{-}}^{\theta} y(t)=y(t), \\
& D_{a^{+}}^{\theta}(t-a)^{\gamma-1}=\frac{\Gamma(\gamma)}{\Gamma(\gamma-\theta)}(t-a)^{\gamma-\theta-1},
\end{aligned}
$$

and

$$
D_{b^{-}}^{\theta}(b-t)^{\gamma-1}=\frac{\Gamma(\gamma)}{\Gamma(\gamma-\theta)}(b-t)^{\gamma-\theta-1}, \quad \gamma>[\theta]+1 .
$$

Next we need the following definitions and a theorem for the development of our results.

Let $X$ and $Y$ be two Banach spaces (real), and let us define a linear operator $L: \operatorname{dom} L \subset$ $X \rightarrow Y$. Then we have the following definition.

Definition 4 A linear operator $L$ is called Fredholm operator with index zero if $\operatorname{Im} L$ is a closed subset in $Y$ and $\operatorname{dim} \operatorname{ker} L=\operatorname{codim} \operatorname{Im} L<\infty$.

Now if we define $P: X \rightarrow X$ and $Q: Y \rightarrow Y$ as continuous projections such that $\operatorname{Im} P=$ $\operatorname{ker} L, \operatorname{ker} Q=\operatorname{Im} L$. Then

$$
X=\operatorname{ker} P \oplus \operatorname{ker} L, \quad Y=\operatorname{Im} Q \oplus \operatorname{Im} L,
$$

which leads to

$$
\left.L\right|_{\text {ker } P \cap \operatorname{dom} L}: \operatorname{dom} L \cap \operatorname{ker} P \rightarrow \operatorname{Im} L
$$

is invertible, and we denote its inverse by $K_{P}$.

Definition 5 Let $\Omega \subset X$ be a bounded open subset and $\operatorname{dom} L \cap \Omega \neq \emptyset$. Then the map $N$ : $X \rightarrow Y$ is called $L$-compact on $\bar{\Omega}$ if the map $Q N(\bar{\Omega})$ is bounded and further $K_{P}(I-Q N)$ : $\bar{\Omega} \rightarrow X$ is compact.

Note that since $\operatorname{Im} Q$ is isomorphic to $\operatorname{ker} L$, that is, $J: \operatorname{Im} Q \rightarrow \operatorname{ker} L$ isomorphism, the equation $L x=N x$ is equivalent to

$$
x=(P+J Q N) x+K P(I-Q) N x .
$$

The next theorem is given in [21].

Theorem 6 Let L be a Fredholm operator with index zero and $N$ be L-compact on $\bar{\Omega}$. Further, the following conditions are satisfied: 
(1) $L x \neq \lambda N x, \forall(x, \lambda) \in[(\operatorname{dom} L \backslash \operatorname{ker} L) \cap \partial \Omega] \times(0,1)$;

(2) $N x \notin \operatorname{Im} L, \forall x \in \operatorname{ker} L \cap \partial \Omega$;

(3) If $Q: Y \rightarrow Y$ is a projection and $\operatorname{deg}\left(\left.Q N\right|_{\operatorname{ker} L}, \Omega \cap \operatorname{ker} L, 0\right) \neq 0$ such that $\operatorname{Im} L=\operatorname{ker} Q$, then there is at least one solution for equation $L x=N x$ in $\operatorname{dom} L \cap \bar{\Omega}$.

\section{Some lemmas}

Let $X=C([0,1], \mathbb{R})$ and operator $L: \operatorname{dom} L \subset X \rightarrow X$ be given by

$$
L x=D_{1^{-}}^{\theta} D_{0^{+}}^{v} x
$$

where

$$
\operatorname{dom} L=\left\{x \in X, D_{1^{-}}^{\theta} D_{0^{+}}^{v} x \in X, x(0)=0 \text {, and } D_{0^{+}}^{v} x(1)=D_{0^{+}}^{v} x(0)\right\}
$$

Let $N: X \rightarrow X$ be defined by $N x(t)=f(t, x(t))$, then problem $(\mathrm{P})$ is equivalent to the equation $L x=N x$ for $t \in[0,1]$.

Lemma 7 Let L be given by (2), then

$$
\begin{aligned}
& \operatorname{ker} L=\left\{x \in \operatorname{dom} L, x(t)=a \frac{t^{v}}{\Gamma(v+1)}, t \in[0,1], a \in \mathbb{R}\right\}, \\
& \operatorname{Im} L=\left\{y \in X, \int_{0}^{1} s^{\theta-1} y(s) d s=0\right\} .
\end{aligned}
$$

Proof Let $x \in \operatorname{ker} L$. From Lemma 3, the equation $L x=0$ has a solution

$$
x(t)=I_{0^{+}}^{v}(a)+b=\frac{a}{\Gamma(v)} \int_{0}^{t}(t-s)^{v-1} d s+b, \quad a, b \in \mathbb{R} .
$$

By applying the boundary conditions (BC), we can easily get $b=0$, then it follows that $x(t)=a \frac{t^{v}}{\Gamma(v+1)}, a \in \mathbb{R}$.

Now, let $y \in \operatorname{Im} L$, then there exists a function $x \in \operatorname{dom} L$ such that

$$
L x(t)=D_{1^{-}}^{\theta}\left(D_{0^{+}}^{v} x(t)\right)=y(t)
$$

Applying the operator $I_{1^{-}}^{\theta}$ then $I_{0^{+}}^{v}$ to both sides of equation (3), we get

$$
x(t)=I_{0^{+}}^{v} I_{1^{-}}^{\theta} y(t)+I_{0^{+}}^{v}(a)+b=I_{0^{+}}^{v} I_{1^{-}}^{\theta} y(t)+\frac{a}{\Gamma(v)} \int_{0}^{t}(t-s)^{v-1} d s+b
$$

Condition $x(0)=0$ implies

$$
x(t)=I_{0^{+}}^{v} I_{1^{-}}^{\theta} y(t)+I_{0^{+}}^{v}(a)
$$

Since $D_{0^{+}}^{v} x(1)=a=D_{0^{+}}^{v} x(0)=I_{1^{-}}^{\theta} y(0)+a$, thus $I_{1^{-}}^{\theta} y(0)=0$, i.e.,

$$
\int_{0}^{1} s^{\theta-1} y(s) d s=0
$$


Conversely, let $y \in X$ and satisfy (4), set $x(t)=I_{0^{+}}^{v} I_{1^{-}}^{\theta} y(t)+I_{0^{+}}^{v} a, a \in \mathbb{R}$, then $x \in \operatorname{dom} L$ and satisfies $L x=y$, thus $y \in \operatorname{Im} L$. It follows that the proof is complete.

Lemma 8 The operator $L: \operatorname{dom} L \subset X \rightarrow X$ is a Fredholm operator with index zero. The linear projection operators $P, Q: X \rightarrow X$ satisfy

$$
\begin{aligned}
& P x(t)=D_{0^{+}}^{v} x(1) \frac{t^{v}}{\Gamma(v+1)}, \\
& Q y(t)=\theta \int_{0}^{1} s^{\theta-1} y(s) d s .
\end{aligned}
$$

Furthermore, the operator $K_{p}: \operatorname{Im} L \rightarrow \operatorname{dom} L \cap \operatorname{ker} P$ defined by $K_{p} y=I_{0^{+}}^{v} I_{1^{-}}^{\theta} y$ is the inverse of $\left.L\right|_{\mathrm{dom} L \cap \mathrm{ker} P}$ and satisfies

$$
\left\|K_{p} y\right\| \leq \frac{1}{(\theta+v-1)}\|y\| .
$$

Proof The continuous operator $Q$ is a projector, indeed

$$
\begin{aligned}
Q^{2} y(t) & =Q(Q y)(t)=\theta \int_{0}^{1} s^{\theta-1} Q y(s) d s=\theta \int_{0}^{1} s^{\theta-1}\left(\theta \int_{0}^{1} r^{\theta-1} y(r) d r\right) d s \\
& =\left(\theta \int_{0}^{1} s^{\theta-1}\right)\left(\theta \int_{0}^{1} r^{\theta-1} y(r) d r\right)=\theta \int_{0}^{1} r^{\theta-1} y(r) d r=Q y(t) .
\end{aligned}
$$

It is easy to check that $\operatorname{Im} L=\operatorname{ker} Q$. Let $y=(y-Q y)+Q y$, then it follows that

$$
y-Q y \in \operatorname{ker} Q=\operatorname{Im} L, \quad Q y \in \operatorname{Im} Q
$$

and

$$
\operatorname{Im} Q \cap \operatorname{Im} L=\{0\},
$$

so that $X=\operatorname{Im} L \oplus \operatorname{Im} Q$. Then we obtain

$$
\operatorname{dim} \operatorname{ker} L=1=\operatorname{dim} \operatorname{Im} Q=\operatorname{codim} \operatorname{Im} L=1,
$$

that is, $L$ is a Fredholm operator with index zero.

Now we claim that the continuous operator $P$ is a projector. In fact

$$
\begin{aligned}
P^{2} x(t) & =P(P x(t))=\left(D_{0^{+}}^{v} P x\right)(1) \frac{t^{v}}{\Gamma(v+1)} \\
& =\frac{t^{v}}{\Gamma(v+1)} D_{0^{+}}^{v} x(1) D_{0^{+}}^{v}\left(\frac{t^{v}}{\Gamma(v+1)}\right)(1) \\
& =D_{0^{+}}^{v} x(1) \frac{t^{v}}{(\Gamma(v+1))^{2}} D_{0^{+}}^{v}\left(t^{v}\right)(1) \\
& =D_{0^{+}}^{v} x(1) \frac{t^{v}}{\Gamma(v+1)}=P x(t)
\end{aligned}
$$


Obviously, $\operatorname{Im} P=\operatorname{ker} L$. Then, setting $x=(x-P x)+P x$, we have that $X=\operatorname{ker} P+\operatorname{ker} L$. Further this leads to $\operatorname{ker} L \cap \operatorname{ker} P=\{0\}$, that is, $X=\operatorname{ker} L \oplus \operatorname{ker} P$.

Now, we show that a generalized inverse of $L$ is $K_{P}$. If we let $y \in \operatorname{Im} L$, in view of Lemma 3 , it yields

$$
\left(L K_{p}\right) y(t)=\left(D_{1^{-}}^{\theta} D_{0^{+}}^{v}\right)\left(K_{p} y(t)\right)=D_{1^{-}}^{\theta} D_{0^{+}}^{v}{ }_{0^{+}}^{v} I_{1^{-}}^{\theta} y(t)=y(t),
$$

and for $x \in \operatorname{dom} L \cap \operatorname{ker} P$, we obtain

$$
\begin{aligned}
\left(K_{p} L\right) x(t) & =\left(K_{p}\right) D_{1^{-}}^{\theta} D_{0^{+}}^{v} x(t)=I_{0^{+}}^{v} I_{1^{-}}^{\theta} D_{1^{-}}^{\theta} D_{0^{+}}^{v} x(t) \\
& =x(t)+D_{0^{+}}^{v} x(1) \frac{t^{v}}{\Gamma(v+1)}+x(0) .
\end{aligned}
$$

Since $x(0)=0$ and $P x=0$, we get

$$
\left(K_{p} L\right) x(t)=x(t)
$$

This shows that

$$
K_{p}=\left(\left.L\right|_{\operatorname{dom} L \cap \operatorname{ker} P}\right)^{-1} .
$$

Applying the definition of $K_{p}$, we obtain

$$
\begin{aligned}
\left|\left(K_{p} y\right)(t)\right|= & \mid I_{0^{+}}^{v} I_{1^{\theta}-y(t) \mid} \\
= & \frac{1}{\Gamma(\theta) \Gamma(v)} \int_{0}^{t}\left(\int_{0}^{r}(t-s)^{v-1}(r-s)^{\theta-1} d s\right) y(r) d r \\
& +\frac{1}{\Gamma(\theta) \Gamma(v)} \int_{t}^{1}\left(\int_{0}^{t}(t-s)^{v-1}(r-s)^{\theta-1} d s\right) y(r) d r \\
\leq & \frac{1}{\Gamma(\theta) \Gamma(v)}\left(\int_{0}^{t}\left(\int_{0}^{r}(r-s)^{\theta+v-2} d s\right) y(r) d r\right. \\
& \left.+\int_{t}^{1}\left(\int_{0}^{t}(t-s)^{\theta+v-2} d s\right) y(r) d r\right) \\
= & \frac{1}{\Gamma(\theta) \Gamma(v)(\theta+v-1)}\left(\int_{0}^{t} r^{\theta+v-1} y(r) d r+t^{\theta+v-1} \int_{0}^{t} y(r) d r\right) \\
\leq & \frac{1}{(\theta+v-1)}\|y\|,
\end{aligned}
$$

that is,

$$
\left\|K_{p} y\right\| \leq \frac{1}{(\theta+v-1)}\|y\| .
$$

This completes the proof.

\section{Existence of solutions}

In order to solve problem (P), we assume the following conditions: 
(H1) There exist some functions $\alpha, \beta \in C\left([0,1], \mathbb{R}^{+}\right)$such that

$$
|f(t, x)| \leq \alpha(t)|x|+\beta(t)
$$

provided $1-A\|\alpha\|>0$, where

$$
A=\left(\frac{1}{\Gamma(v+1) \Gamma(\theta+1)}+\frac{1}{(\theta+v-1)}\right)
$$

for $t \in[0,1]$ and $x \in \mathbb{R}$.

(H2) There exists a constant $M>0$ such that if $\left|D_{0^{+}}^{v} x(t)\right|>M$, then

$$
\int_{0}^{1} s^{\theta-1} f(s, x(s)) d s \neq 0
$$

(H3) There exists a constant $M^{*}>0$ such that, for

$$
x(t)=c_{0} \frac{t^{v}}{\Gamma(v+1)} \in \operatorname{ker} L
$$

with $\left|c_{0}\right|>M^{*}$, either

$$
c_{0} \int_{0}^{1} s^{\theta-1} f(s, x(s)) d s<0
$$

or

$$
c_{0} \int_{0}^{1} s^{\theta-1} f(s, x(s)) d s>0
$$

Lemma 9 Consider that condition (H1) holds. Then $N$ is L-compact on $\bar{\Omega}$ where $\Omega$ is a bounded open subset of $X$ such that $\operatorname{dom} L \cap \bar{\Omega} \neq \emptyset$.

Proof We will show that $Q N(\bar{\Omega})$ is a bounded operator and $K_{P}(I-Q N)(\bar{\Omega})$ is a compact operator. Since $\Omega$ is a bounded set, then there is a constant $r>0$ such that $\|x\| \leq r, \forall x \in \bar{\Omega}$. Let $x \in \bar{\Omega}$, then in view of condition (H1) we have

$$
|Q N x| \leq \theta \int_{0}^{1} s^{\theta-1}|f(s, x(s))| d s \leq r\|\alpha\|+\|\beta\|
$$

which yields $Q N(\bar{\Omega})$ is a bounded operator.

Next, we prove that $K_{P}(I-Q) N(\bar{\Omega})$ is compact. For $x \in \bar{\Omega}$, and by condition (H1), we get

$$
\|N x\| \leq r\|\alpha\|+\|\beta\|
$$

On the other hand, using the definition of $K_{P}$ and together with (5), (10), and (11), we get

$$
\left\|K_{P}(I-Q) N x\right\| \leq \frac{1}{(\theta+v-1)}\|(I-Q) N x\|
$$




$$
\begin{aligned}
& \leq \frac{1}{(\theta+v-1)}[\|N x\|+\|Q N x\|] \\
& \leq \frac{2(r\|\alpha\|+\|\beta\|)}{(\theta+v-1)} .
\end{aligned}
$$

It follows that

$$
K_{P}(I-Q) N(\bar{\Omega})
$$

is actually uniformly bounded.

Now we prove $K_{P}(I-Q) N(\bar{\Omega})$ is equicontinuous. For this, let $x \in \bar{\Omega}$, and for any $t_{1}, t_{2} \in$ $[0,1], t_{1}<t_{2}$, we have

$$
\begin{aligned}
\mid( & \left.K_{P}(I-Q) N x\right)\left(t_{1}\right)-\left(K_{P}(I-Q) N x\right)\left(t_{2}\right) \mid \\
= & \left|I_{0^{+}}^{v} I_{1^{-}}^{\theta}(I-Q) N x\left(t_{1}\right)-I_{0^{+}}^{v} I_{1^{-}}^{\theta}(I-Q) N x\left(t_{2}\right)\right| \\
= & \frac{1}{\Gamma(v)} \mid \int_{0}^{t_{1}}\left(t_{1}-s\right)^{\nu-1} I_{1^{-}}^{\theta}(I-Q) N x(s) d s \\
& \quad-\int_{0}^{t_{2}}\left(t_{2}-s\right)^{v-1} I_{1^{-}}^{\theta}(I-Q) N x(s) d s \mid \\
\leq & \int_{0}^{t_{1}}\left(\left(t_{1}-s\right)^{v-1}-\left(t_{2}-s\right)^{v-1}\right)\left|I_{1^{-}}^{\theta}(I-Q) N x(s)\right| d s \\
& \quad+\int_{t_{1}}^{t_{2}}\left(t_{2}-s\right)^{v-1}\left|I_{1^{-}}^{\theta}(I-Q) N x(s)\right| d s .
\end{aligned}
$$

Let us estimate the term $\left|I_{1^{-}}^{\theta}(I-Q) N x(s)\right|$. We have

$$
\begin{aligned}
\left|I_{1^{-}}^{\theta}(I-Q) N x(s)\right| & =\frac{1}{\Gamma(\theta)} \int_{s}^{1}(r-s)^{\theta-1}|(I-Q) N x(r)| d r \\
& \leq \frac{2(r\|\alpha\|+\|\beta\|)}{\Gamma(\theta+1)},
\end{aligned}
$$

thus it is bounded and (13) becomes

$$
\begin{aligned}
& \left|\left(K_{P}(I-Q) N x\right)\left(t_{1}\right)-\left(K_{P}(I-Q) N x\right)\left(t_{2}\right)\right| \\
& \quad \leq \frac{2(r\|\alpha\|+\|\beta\|)}{\Gamma(\theta+1)}\left(\int_{0}^{t_{1}}\left(\left(t_{1}-s\right)^{v-1}-\left(t_{2}-s\right)^{v-1}\right) d s+\int_{t_{1}}^{t_{2}}\left(t_{2}-s\right)^{v-1} d s\right) \\
& \quad=\frac{2(r\|\alpha\|+\|\beta\|)}{\Gamma(\theta+1)}\left(\frac{t_{1}{ }^{v}-t_{2}{ }^{v}+2\left(t_{2}-t_{1}\right)^{v}}{v}\right) \rightarrow 0, \quad \text { as } t_{1} \rightarrow t_{2} .
\end{aligned}
$$

Thus it follows that $K_{P}(I-Q) N(\bar{\Omega})$ is equicontinuous on $[0,1]$. Hence, we easily deduce that $K_{P}(I-Q N): \bar{\Omega} \rightarrow X$ is a compact operator.

Lemma 10 Let $\Omega_{1}=\{x \in \operatorname{dom} L \backslash \operatorname{ker} L: L x=\lambda N x$ for some $\lambda \in(0,1)\}$. If condition (H1) holds, then $\Omega_{1}$ is bounded. 
Proof Suppose that $x \in \Omega_{1}$, then $x=(x-P x)+P x \in \operatorname{dom} L \backslash \operatorname{ker} L$. That is, $(I-P) x \in \operatorname{dom} L \cap$ ker $P$ and $P x \in \operatorname{ker} L$, i.e., $L P x=0$, thus from Lemma 8 , we get

$$
\begin{aligned}
\|(I-P) x\| & =\left\|K_{p} L(I-P) x\right\| \leq \frac{1}{(\theta+v-1)}\|L(I-P) x\| \\
& =\frac{1}{(\theta+v-1)}\|L x\|=\frac{1}{(\theta+v-1)}\|N x\| \\
& \leq \frac{1}{(\theta+v-1)}(\|\alpha\|\|x\|+\|\beta\|) .
\end{aligned}
$$

That means

$$
\|P x\| \leq \frac{\left\|D_{0^{+}}^{v} x\right\|}{\Gamma(v+1)}
$$

Since $L x=\lambda N x$, then

$$
\left|D_{0^{+}}^{v} x(t)\right|=\lambda\left|I_{1^{-}}^{\theta} f(t, x(t))\right| \leq \frac{1}{\Gamma(\theta+1)}(\|\alpha\|\|x\|+\|\beta\|)
$$

then (15) can be estimated as

$$
\|P x\| \leq \frac{(\|\alpha\|\|x\|+\|\beta\|)}{\Gamma(v+1) \Gamma(\theta+1)} .
$$

Using (14) and (17) yields

$$
\begin{aligned}
\|x\| & \leq\|P x\|+\|(I-P) x\| \\
& \leq \frac{(\|\alpha\|\|x\|+\|\beta\|)}{\Gamma(v+1) \Gamma(\theta+1)}+\frac{(\|\alpha\|\|x\|+\|\beta\|)}{(\theta+v-1)} \\
& =A(\|\alpha\|\|x\|+\|\beta\|),
\end{aligned}
$$

thus

$$
\|x\| \leq \frac{A}{1-A\|\alpha\|}\|\beta\|<\infty
$$

which shows that $\Omega_{1}$ is a bounded set.

Lemma 11 Assume that (H2) holds. Then the set

$$
\Omega_{2}=\{x \in \operatorname{ker} L: N x \in \operatorname{Im} L\}
$$

is bounded.

Proof Let $x \in \Omega_{2}$. Since $x \in \operatorname{ker} L$, then $x(t)=a \frac{t^{v}}{\Gamma(v+1)}, a \in \mathbb{R}, \operatorname{Im} L=\operatorname{ker} Q$, and $Q N x=0$. Therefore

$$
\int_{0}^{1} s^{\theta-1} f(s, x(s)) d s=0
$$


Condition (H2) implies that there exists $\tau \in[0,1]$ such that $\left|D_{0^{+}}^{v} x(\tau)\right| \leq M$, thus $|a| \leq M$, so $\|x\| \leq \frac{M}{\Gamma(v+1)}$, hence $\Omega_{2}$ is a bounded set.

Lemma 12 Assume that conditions $(\mathrm{H} 2)$ and $(\mathrm{H} 3)$ hold. Then the set

$$
\Omega_{3}=\{x \in \operatorname{ker} L:-\lambda J x+(1-\lambda) Q N x=0, \lambda \in[0,1]\}
$$

is bounded, where $J: \operatorname{ker} L \rightarrow \operatorname{Im} Q$ is a linear isomorphism given by

$$
J\left(c \frac{t^{v}}{\Gamma(v+1)}\right)=c, \quad \forall c \in \mathbb{R}, t \in[0,1] .
$$

Proof Let $x_{0} \in \Omega_{3}$. Since $\lambda J x_{0}=(1-\lambda) Q N x_{0}$, then

$$
\lambda c_{0}=(1-\lambda) \theta \int_{0}^{1} s^{\theta-1} f\left(s, x_{0}(s)\right) d s .
$$

If $\lambda=0$, then

$$
\int_{0}^{1} s^{\theta-1} f\left(s, x_{0}(s)\right) d s=0 .
$$

From condition (H2), there exists $\varsigma \in[0,1]$ such $\left|D_{0^{+}}^{v} x_{0}(\varsigma)\right|=\left|c_{0}\right| \leq M$, thus $\left\|x_{0}\right\| \leq \frac{M}{\Gamma(v+1)}$.

If $\lambda=1$, then $c_{0}=0$. Now let $0<\lambda<1$, and assume that (8) holds. Since $x_{0}(t)=c_{0} \frac{t^{v}}{\Gamma(v+1)} \in$ $\operatorname{ker} L$, with $\left|c_{0}\right|>M^{*}$, then

$$
\lambda c_{0}^{2}=(1-\lambda) c_{0} \theta \int_{0}^{1} s^{\theta-1} f\left(s, x_{0}(s)\right) d s<0,
$$

which contradicts the fact that $\lambda c_{0}^{2} \geq 0$. So $\left|c_{0}\right| \leq M^{*}$, which gives $\left\|x_{0}\right\|=\frac{\left|c_{0}\right|}{\Gamma(v+1)}$, that means $\Omega_{3}$ is bounded. Similarly, if we assume that (9) holds, then

$$
\Omega_{3}=\{x \in \operatorname{ker} L: \lambda J x+(1-\lambda) Q N x=0, \lambda \in[0,1]\}
$$

is a bounded set.

Theorem 13 Assume that conditions $(\mathrm{H} 1)-(\mathrm{H} 3)$ hold. Then problem $(\mathrm{P})$ has at least one solution in $X$.

Proof We can easily prove that using Lemma 8 and Lemma 9, the conditions of Theorem 6 are satisfied. Then the proof follows similar steps as in [15].

Example 14 Consider problem $(\mathrm{P})$ with

$$
\begin{aligned}
& \theta=0.5, \quad \text { and } \quad v=0.8, \\
& f(t, x)=10^{-1}(1+t)|\sin x|+e^{-t}, \quad(t, x) \in[0,1] \times \mathbb{R},
\end{aligned}
$$

then condition (H1) is fulfilled. In fact,

$$
|f(t, x)| \leq \alpha(t)|x|+\beta(t), \quad \text { with } \alpha(t)=10^{-1}(1+t), \beta(t)=e^{-t} .
$$

We have $A=4.5448$ and $1-A\|\alpha\|=0.54552>0$. 
Condition (H2) holds, indeed

$$
\int_{0}^{1} s^{\theta-1} f(s, x(s)) d s \geq \int_{0}^{1} s^{\theta-1} e^{-s} d s=1.4936
$$

thus condition (H2) is satisfied for any constant $M>0$.

Condition (H3) is also satisfied. In fact, for $M^{*}=1>0$, such that for any $x(t)=c_{0} \frac{t^{v}}{\Gamma(v+1)} \in \operatorname{ker} L$ with $\left|c_{0}\right|>M^{*}$, we have

$$
\int_{0}^{1} s^{\theta-1} f(s, x(s)) d s \geq 1.4936>0
$$

Then

$$
c_{0} \int_{0}^{1} s^{\theta-1} f(s, x(s)) d s>0, \quad \text { if } c_{0}>0
$$

or

$$
c_{0} \int_{0}^{1} s^{\theta-1} f(s, x(s)) d s<0, \quad \text { if } c_{0}<0
$$

We conclude by Theorem 13 that problem $(\mathrm{P})$ has a solution in $X$.

\section{Conclusion}

Nonlinear fractional integro-differential equations are important and widely applied in many areas. In particular to have mixed fractional terms on both sides, that is, having fractional integrals or fractional derivatives on the left- and right-hand side respectively, is an important class that is not fully studied in the literature. There are some real difficulties to examine the existence and uniqueness of solutions for these types of equations, and further properties for these types of equations have been studied by few researchers using different techniques (see, for example, $[4,9,14]$ for partial treatment).

In this work we establish sufficient conditions and prove that there is at least one solution for problem $(\mathrm{P})$ :

$$
\left\{\begin{array}{l}
D_{1^{-}}^{\theta} D_{0^{+}}^{v} x(t)=f(t, x(t)), \\
x(0)=0, \quad D_{0^{+}}^{v} x(1)=D_{0^{+}}^{v} x(0) \quad \text { for } t \in(0,1),
\end{array}\right.
$$

under certain condition.

\section{Acknowledgements}

The authors would like to thank anonymous referees and editors for their valuable comments and constructive suggestions that improved the present study.

\section{Funding}

No funding available.

Availability of data and materials

Data sharing is not applicable to this article as no datasets were generated or analysed during the current study. 
Authors' contributions

The authors contributed equally and significantly in writing this paper. Both authors read and approved the final manuscript.

\section{Author details}

'Laboratory of Advanced Materials, Department of Mathematics, University Badji Mokhtar-Annaba, P.O. Box 12, 23000, Annaba, Algeria. ${ }^{2}$ Department of Mathematics and Institute for Mathematcal Research, Universiti Putra Malaysia, 43400, Serdang, Malaysia.

\section{Publisher's Note}

Springer Nature remains neutral with regard to jurisdictional claims in published maps and institutional affiliations.

Received: 3 June 2020 Accepted: 16 October 2020 Published online: 27 October 2020

\section{References}

1. Podlubny, I.: Fractional Differential Equation. Academic Press, Sain Diego (1999)

2. Samko, S.G., Kilbas, A.A., Marichev, O.I.: Fractional Integrals and Derivatives, Theory and Applications. Gordon \& Breach, Yverdon (1993)

3. Ahmad, B., Ntouyas, S.K., Alsaedi, A.: Existence theory for nonlocal boundary value problems involving mixed fractional derivatives. Nonlinear Anal., Model. Control 24, 937-957 (2019)

4. Ahmad, B., Broom, A., Alsaedi, A., Ntouyas, S.K.: Nonlinear integro-differential equations involving mixed right and left fractional derivatives and integrals with nonlocal boundary data. Mathematics 8, 336 (2020). https://doi.org/10.3390/math8030336

5. Bai, Z:: On solutions of some fractional m-point boundary value problems at resonance. Electron. J. Qual. Theory Differ. Equ. 2010, Article ID 37 (2010)

6. Baleanu, D., Diethelm, K., Scalas, E., Trujillo, J.J.: Fractional Calculus Models and Numerical Methods. World Scientific, Singapore (2012)

7. Blaszczyk, T., Ciesielski, M.: Numerical solution of Euler-Lagrange equation with Caputo derivatives. Adv. Appl. Math. Mech. 9(1), 173-185 (2017)

8. Chen, Y., Tang, X.: Positive solutions of fractional differential equations at resonance on the half-line. Bound. Value Probl. 2012, 64 (2012)

9. Djebali, S., Aoun, A.G.: Resonant fractional differential equations with multi-point boundary conditions on $(0, \infty)$. J. Nonlinear Funct. Anal. 2019, Article ID xx (2019)

10. Guezane-Lakoud, A., Kılıçman, A.: Unbounded solution for a fractional boundary value problem. Adv. Differ. Equ. 2014, 154 (2014)

11. Guezane-Lakoud, A., Khaldi, R.: On a boundary value problem at resonance on the half line. J. Fract. Calc. Appl. 8 , 159-167 (2017)

12. Guezane-Lakoud, A., Rodríguez-López, R.: On a fractional boundary value problem in a weighted space. SeMA J. 75, 435-443 (2018)

13. Guezane-Lakoud, A., Khaldi, R., Torres, D.F.M.: On a fractional oscillator equation with natural boundary conditions. Prog. Fract. Differ. Appl. 3(3), 191-197 (2017)

14. Guezane Lakoud, A., Khaldi, R., Kılıçman, A.: Existence of solutions for a mixed fractional boundary value problem. Adv. Differ. Equ. 2017, 164 (2017)

15. Frioui, A., Guezane-Lakoud, A., Khaldi, R.: Fractional boundary value problems on the half line. Opusc. Math. 37(2), 265-280 (2017)

16. Ji, Y., Jiang, W., Qiu, J.: Solvability of fractional differential equations with integral boundary conditions at resonance. Topol. Methods Nonlinear Anal. 42(2), 461-479 (2013)

17. Jiang, W.: The existence of solutions to boundary value problems of fractional differential equations at resonance. Nonlinear Anal. TMA 74, 1987-1994 (2011)

18. Kilbas, A.A., Srivastava, H.M., Trujillo, J.J.: Theory and Applications of Fractional Differential Equations. North-Holland Mathematics Studies. Elsevier, Amsterdam (2006)

19. Kılıçman, A., Damag, F.H.M.: Some solution of the fractional iterative integro-differential equations. Malaysian J. Math. Sci. 12(1), 121-141 (2018)

20. Damag, F., Kilıçman, A., Dutta, H., Ibrahim, R.: A note on the lower and upper solutions of hybrid-type iterative fractional differential equations. Nat. Acad. Sci. Lett. (2019). https://doi.org/10.1007/s40009-019-00863-5

21. Khaldi, R., Guezane-Lakoud, A.: Minimal and maximal solutions for a fractional boundary value problem at resonance on the half line. Fract. Differ. Calc. 8(2), 299-307 (2018)

22. Mawhin, J.: Topological Degree Methods in Nonlinear Boundary Value Problems. NSFCBMS Regional Conference Series in Mathematics. Am. Math. Soc., Providence (1979)

23. Song, S., Cui, Y.: Existence of solutions for integral boundary value problems of mixed fractional differential equations under resonance. Bound. Value Probl. 2020, 23 (2020)

24. Liu, Y.: A new method for converting boundary value problems for impulsive fractional differential equations to integral equations and its applications. Adv. Nonlinear Anal. 8(1), 386-454 (2019)

25. Qu, H., Liu, X.: Existence of nonnegative solutions for a fractional $m$-point boundary value problem at resonance. Bound. Value Probl. 2013, Article ID 127 (2013) 